\title{
Microstructure evolution of allotropic materials during thermomechanical processing
}

\author{
Cecilia Poletti ${ }^{1, a}$, Fernando Warchomicka ${ }^{2, b}$, Martina Dikovits ${ }^{1, c}$ \\ Simon Großeiber ${ }^{2, d}$
}

\author{
${ }^{1}$ Graz University of Technology. Inst. Mat. Sci and Weld. Kopernikusgasse 24/l. 8010 Graz, Austria \\ ${ }^{2}$ Vienna University of Technology. Inst. Mat. Sci. and Techn. Karlsplatz 14. 1040 Vienna, Austria \\ acecilia.poletti@tugraz.at, 'fwarchom@pop.tuwien.ac.at, 'martina.dikovits@tugraz.at, \\ dsimon.grosseiber@tuwien.ac.at
}

Keywords: phase transformation, hot deformation, titanium alloys, low carbon steels

\begin{abstract}
The microstructure developed during hot deformation is the result of deformation mechanisms such as dynamic recovery and dynamic recrystallization. Hot deformation can also result in damage and flow localisation, especially in multiphase metal based materials.

Several models have been proposed to correlate the parameters of the deformation process (temperature, strain and strain rate) with the flow behaviour such as the processing maps. They were developed based on the dynamic materials model (DMM) and later a modified DMM introduced some changes in the calculation of the processing maps.

The correlation of the relevant microstructural changes with thermodynamic parameters are tested and discussed. The data was obtained by using the Gleeble simulator with in situ quenching facilities. Microstructural studies related to the hot deformation of metals were carried out based on alpha-beta and near beta titanium alloys and on low carbon steels. The results are correlated with the efficiency of power dissipation, and the constitutive equations. In diffusion controlled processes such as dynamic recovery, dynamic recrystallization, phase transformation and pore coarsening are related to high power efficiency, and to low $n$ exponent. The efficiency of power dissipation is more sensitive to the deformation parameters than the constitutive equations for materials with phase transformation.
\end{abstract}

\section{Introduction}

Deformation mechanisms above the homologous temperature are not always easy to describe. It was observed in some cases that these controversies are the result of experimental artefacts, such as slow cooling, barrelling (inhomogeneous strain and strain rates distributions) and inappropriate characterization methods. These differences in interpretation can be avoided by determining the exact parameters of deformation in the deformed samples with the microstructure.

The multiphase materials present additional challenges in interpreting the hot deformation mechanism. The distribution and shape of the constituent phases before deformation can result in different types of deformation. Thus, alpha-beta titanium alloys can present softening by kinking [1] if the starting microstructure is lamellar, while a fine alpha structure can result in superplasticity [2]. Furthermore, each phase will be deformed at elevated temperature by different mechanisms, as for example dynamic recrystallization (DRX) in austenite and dynamic recovery (DRV) in ferrite. Furthermore, damage due to heterogeneous strain distribution in multiphase materials can occur. Finally, phase transformation in allotropic materials is influenced by the hot deformation.

In any case, it is relevant but not always trivial to recognize the controlling or predominant deformation mechanism. With this objective, constitutive equations are constructed using experimental flow data. The obtained parameters are used as complementary tools for the description of the deformation mechanism, although sometimes, and especially for multiphase materials it cannot reflect changes in deformation mechanisms as a function of the temperature and the strain rate. Thus, a parameter such as efficiency of power dissipation is used complementally. 
Constitutive equations The semi-empirical constitutive equations are used to describe the interdependence of $\sigma$ with $\dot{\varepsilon}$ and T during hot deformation. The Zener-Hollomon parameter is $\mathrm{Z}$ defined as

$\mathrm{Z}=\mathrm{A} \dot{\varepsilon} \exp (\mathrm{Q} / \mathrm{RT})$

and can be related with the flow stress and temperature using the Eq2 for low stresses, Eq3 for high stresses, or the universal expression Eq4 [3].

$\mathrm{A}_{\mathrm{P}} \sigma^{\mathrm{n}_{\mathrm{P}}}=\dot{\varepsilon} \exp \left(\mathrm{Q}_{\mathrm{P}} / \mathrm{RT}\right)=\mathrm{Z}_{\mathrm{P}}$

Eq 2

$\mathrm{A}_{\mathrm{E}} \exp \beta \sigma=\dot{\varepsilon} \exp \left(\mathrm{Q}_{\mathrm{P}} / \mathrm{RT}\right)=\mathrm{Z}_{\mathrm{E}}$

Eq 3

$\mathrm{A}[\sinh (\alpha \sigma)]^{\mathrm{n}}=\dot{\varepsilon} \exp \left(\mathrm{Q}_{\mathrm{P}} / \mathrm{RT}\right)=\mathrm{Z}$

Eq 4

$\mathrm{A}, \beta, \alpha$ and $\mathrm{n}$ are material constants, and $\mathrm{P}$ and $\mathrm{E}$ are subscripts related to the power and the exponential laws, respectively. In the constitutive equations $\mathrm{n}$ can be correlated to the deformation mechanism [4].

Efficiency of power dissipation The heuristic processing maps based on dynamic materials model (DMM) developed by Prasad et. al. [5] and modified by Murty and Rao [6] are extensively used providing applicable results for different kind of materials [7]. In the DMM, the material is considered essentially dissipative [5], meaning that no storage of energy takes place. The power dissipation $\mathrm{P}$ is defined as the power that is given to the material due to deformation and which is completely dissipated.

$\mathrm{P}_{\mathrm{T}, \varepsilon}=\sigma \dot{\varepsilon}=\mathrm{G}+\mathrm{J}=\int_{0}^{\dot{\varepsilon}} \sigma \mathrm{d} \dot{\varepsilon}+\int_{0}^{\sigma} \dot{\varepsilon} \mathrm{d} \sigma$

Eq 5

The strain rate sensitivity $\mathrm{m}$, is defined as:

$\mathrm{m}=[\partial(\ln \sigma) / \partial(\ln \dot{\varepsilon})]_{\varepsilon, \mathrm{T}}$

Eq 6

If compared with the power creep law, $\mathrm{m}=1 / \mathrm{n}$ for any given temperature and deformation grade. In the case where the material obeys the power law, then the partition between $J$ and $G$ is the

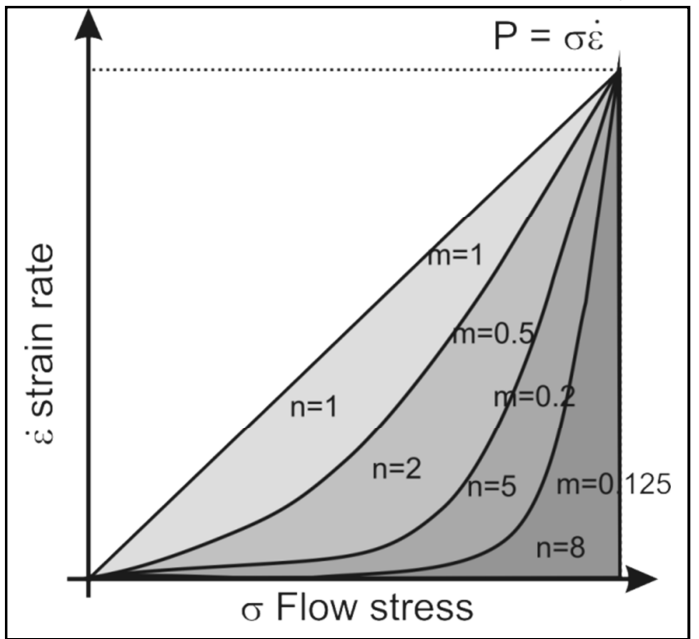
exponent $\mathrm{n}$ or its reciprocal $\mathrm{m}$. The efficiency of power dissipation $\eta$ is defined as a ratio between $J$ and $J_{\max }$. The value of $\mathrm{J}_{\max }$ is obtained for the behaviour of an ideal linear dissipator, meaning $\mathrm{m}=1$, resulting in $\mathrm{J}_{\max }=$ $\mathrm{P} / 2$. At any $\mathrm{T}$ and $\dot{\varepsilon}$

$\eta=\mathrm{J} / \mathrm{J}_{\max }=2 \mathrm{~J} / \mathrm{P}$

Figure 1. Dashed zones representing the meaning of $J$ for materials that can be represented with the power law. It can be observed, that the maximal $J$ value is given for a linear dissipator, meaning for $n=m=1$ or diffusive deformation behaviour

Figure 1 shows the graphical representation of $\mathrm{J}$ from $\mathrm{Eq} 5$ as the area below the curve for different $\mathrm{m}$ and $\mathrm{n}$ values. For materials that do not obey the power law due to high stress, allotropic phase transformation and/or multiphase transformation, Eq 7 can still be used. It can be seen that $\mathrm{J}, \mathrm{n}$ and $\mathrm{m}$ are correlated, and that $\mathrm{J}$ can be used for any kind of flow behaviour. Because the integral $\mathrm{J}$ varies between $0 \mathrm{MPa}$ stress and a value, the $\mathrm{G}$ integral is instead calculated. Eq 7 is used to calculate $\eta$ :

$$
\eta_{\text {Murty and Rao }}=2(\mathrm{P}-\mathrm{G}) / \mathrm{P}=2\left(\sigma \dot{\varepsilon}-\left(\left[\frac{\sigma \dot{\varepsilon}}{\mathrm{m}+1}\right]_{\dot{\varepsilon}=\dot{\varepsilon}_{\text {min }}}+\int_{\dot{\varepsilon}_{\text {min }}}^{\dot{\varepsilon}} \sigma \mathrm{d} \dot{\varepsilon}\right)\right) / \sigma \dot{\varepsilon}
$$

with $\dot{\varepsilon}_{\text {min }}$ being the minimum strain rate experimentally tested. In this case, the integral below the curve shown in Figure 1 is calculated by fitting the experimental data with adequate correlation using numeric or analytical solutions. 


\section{Experimental}

Materials Titanium alloys and one low carbon steel alloy were deformed near their allotropic transformation temperature: $\mathrm{T}_{\beta}$ (beta transus temperature) for titanium alloys and $\mathrm{A}_{\mathrm{r} 3}$ for steels.

Ti-6Al-6V-2Sn produced by powder metallography (CermeTi ${ }^{\circledR}-\mathrm{C}-662$ with lamellar microstructure) with a $\mathrm{T}_{\beta}=945^{\circ} \mathrm{C}$, Ti-6Al-4V alloy (Ti64 ingot bimodal microstructure) with $\mathrm{T}_{\beta}=1000^{\circ} \mathrm{C}$ and the Ti-5Al-5Mo-5V-3Cr-1Zr (Ti55531 globular alpha microstructure) with $\mathrm{T}_{\beta}=803^{\circ} \mathrm{C}$ were tested.

The micro alloyed steel used in this work contains in wt\% $0.194 \mathrm{C}, 1.71 \mathrm{Mn}, 0.47 \mathrm{Si}, 0.11 \mathrm{~V}, 0.022$ $\mathrm{Cr}$ and $0.022 \mathrm{~N}$. The as delivered condition of the material is the continuously cast slab. The samples were taken from near to the surface of the slab, along the casting direction (L). The temperature of austenite to ferrite transformation during cooling at $1 \mathrm{~K} \mathrm{~s}^{-1}$ was $\mathrm{Ar}_{3}=710{ }^{\circ} \mathrm{C}$

Hot deformation tests Cylindrical compression samples of $15 \mathrm{~mm}$ length and $10 \mathrm{~mm}$ of diameter were tested using a Gleeble ${ }^{\circledR} 1500$ servohydraulic machine. Measurement of the diameter was done, Ar gas atmosphere was used to avoid any oxidation or contamination of both samples and anvils and water quenching was performed after deformation. All the samples were ohmic heated at $10 \mathrm{Ks}^{-1}$. Experiments were carried out as described in Table 1.

Table 1. Materials and experiments carried out

\begin{tabular}{|c|c|c|c|c|}
\hline Material & $\begin{array}{l}\text { Temperature } \\
\text { range }\end{array}$ & $\begin{array}{l}\text { Strain rate } \\
\text { range }\end{array}$ & Cooling & Comments \\
\hline Ti662 PM & $650-950^{\circ} \mathrm{C}$ & $0.015-15 \mathrm{~s}^{-1}$ & $\begin{array}{l}\text { Water } \\
\text { quenching }\end{array}$ & $\begin{array}{l}\text { Pre- heat treatment at } 860{ }^{\circ} \mathrm{C} / 3 \mathrm{~min} \text { and } 1 \mathrm{Ks}^{-1} \text { to } \\
\text { deformation temperature }[8]\end{array}$ \\
\hline \multirow[t]{2}{*}{ Ti64 } & $800-1150^{\circ} \mathrm{C}$ & $0.001-100 \mathrm{~s}^{-1}$ & Air cooled & Servotest experiments for flow curves \\
\hline & & & & $\begin{array}{l}\text { Gleeble and in situ WQ to obtain the deformed } \\
\text { microstructure (some parameters) [9] }\end{array}$ \\
\hline Ti55531 & $763-843{ }^{\circ} \mathrm{C}$ & $0.001-10 \mathrm{~s}^{-1}$ & In situ WQ & {$[10]$} \\
\hline Steel with V & $700-950{ }^{\circ} \mathrm{C}$ & $0.0003-0.3 \mathrm{~s}^{-1}$ & In situ WQ & [11] \\
\hline
\end{tabular}

Microstructure. The samples were cut along the compression axis before and after compression and embedded for metallographic preparation. The samples for light optical microscopy (LOM) were ground and polished up to $1 \mu \mathrm{m}$ diamond paste and etched with Kroll and Nital in the case of titanium alloys and steel, respectively. The strain and strain rate distribution within the tested samples were obtained by FEM simulations with DEFORM TM 2D.

Pictures of deformed samples were taken by means of a field emission gun - environmental scanning electron microscope Quanta 200 FEG-SEM was used in the backscatter electron (BSE) mode to distinguish alpha from beta in titanium alloys and ferrite and precipitates in steels due to chemical composition differences. Electron backscatter diffraction (EBSD) and energy dispersive xray spectroscopy (EDX) was performed. In this case, the samples were polished to $0.04 \mu \mathrm{m} \mathrm{SiO}_{2}$ colloidal solution. Pores and damage after hot compression were observed, and the effects of channelling, especially in FEG-SEM devices, were used to obtain contrast between subgrains [12]. Although low sensitivity of the misorientation angles obtained by EBSD compared to other methods [13] leads to an overestimation of the high angle grain boundary (HAGB) content, the results allow satisfactory comparison between samples deformed at different conditions.

\section{Results and discussion}

EBSD measurements showed that the increment of the strain of Ti64 in the two phase region resulted in both, a progressive increment in the crystallographic misorientation within the alpha grains and a change in the shape factor [10],observed in Figure 2a. This same effect is distinguished in Ti662 PM (Figure 2b). The formation of low quantities of new alpha grains took place by cDRX by progressive lattice rotation at the prior grain boundary. In the case of Ti662 the beta phase could 
be retained at room temperature by water quenching, revealing by EBSD measurements subgrain formation (Figure 2c) in this phase. Meta-dynamic recrystallization and static recrystallization can take place after deformation if the temperature is not abruptly decreased. Deformation in the beta region of Ti64 was interpreted in [9] and in the literature [14] as DRX. Further studies on titanium alloys were carried out with better control of the microstructure using in situ water quenching immediately after deformation [15]. The results showed that the beta titanium phase does not recrystallize, and that the new grains formed in Ti64 after the deformation above beta transus temperature are the result of static recrystallization [15].
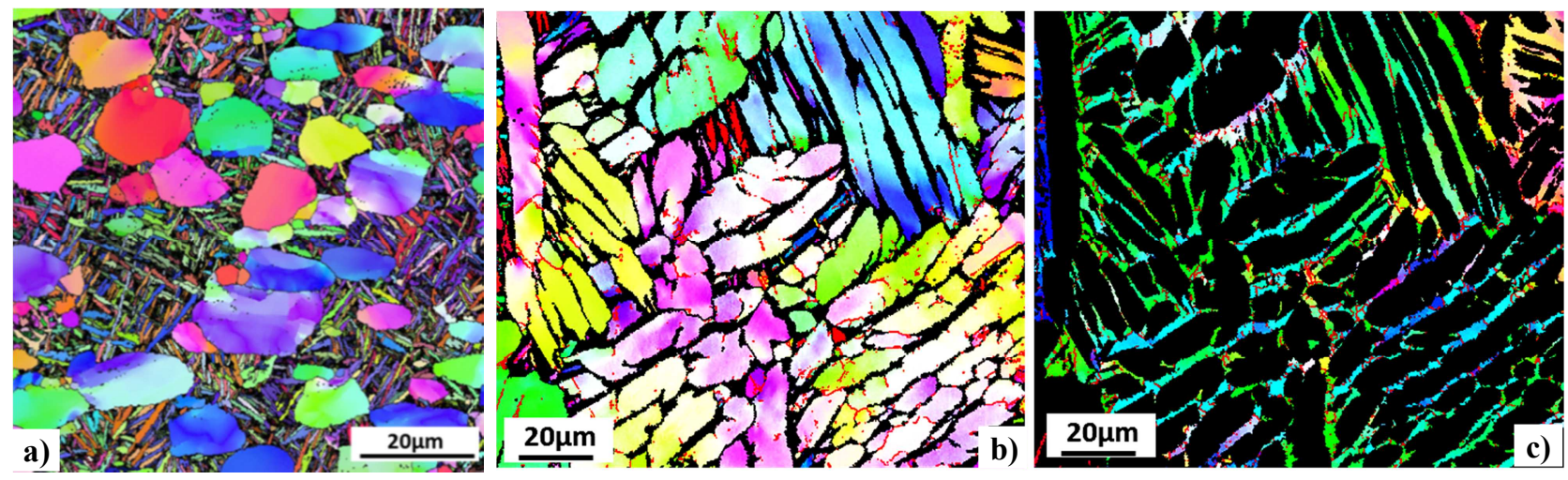

Figure 2. EBSD measurements of a) Ti64 after deformation at $930^{\circ} \mathrm{C}$ and $0.1 \mathrm{~s}^{-1}$ of strain rate and b) $\mathrm{Ti662PM}$ deformed at $650^{\circ} \mathrm{C}$ and $0.1 \mathrm{~s}^{-1}$ showing rotation and increment of the misorientation within the alpha grains. c) beta phase of sample in b) showing formation of subgrain structure. Compression axis is vertical

Dynamic recovery is the main deformation mechanism in the beta phase in titanium alloys. This was confirmed in the studies carried out for Ti55531 [10], in which the beta phase can be retained and frozen by water quenching. Below the beta transus temperature dynamic recovery of the beta phase due to the low stacking fault energy [16] and alpha phase orientation and elongation takes place. An increment in \%HAGB was observed with increasing deformation at low strain rates until saturation is reached. In the case of the two phase field, continuous dynamic recrystallization in beta phase takes place at strains of 1 . At high strain rates progressive lattice rotation of the beta phase, as measured with the EBSD method, is the result of low dynamic recovery. This fact agrees with a similar behaviour in the beta-CEZ alloy at large deformations [18].

Finally, it should be mentioned that in the case of Ti55531at low strain rates, less alpha phase was found for the same temperature. The hypothesis of this peculiar phenomena are: either the material didn't reach the equilibrium due to the slow diffusion of large elements such as Mo and alpha still transforms into beta, or the equilibrium condition was changed by the deformation as proposed in

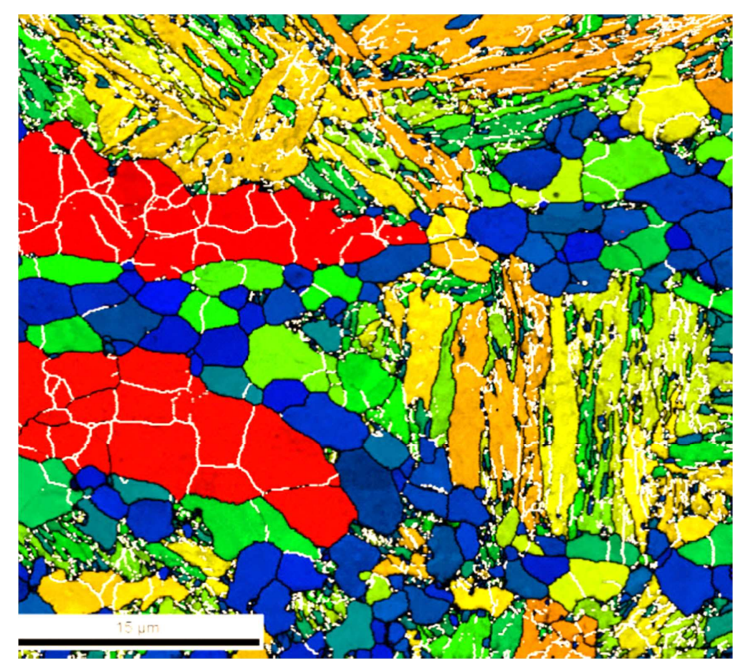
[19] for steels.

The hot deformation of the tested alloyed steel takes place by deformation bands and DRX of austenite below and above the intercritical temperature (around $900^{\circ} \mathrm{C}$ ), respectively and by DRV of ferrite [11]. The transformation from austenite into ferrite additionally occurred during deformation in the tested temperature range, which was accelerated by the deformation. At high strain rates austenite grain refinement occurred by deformation bands below $900^{\circ} \mathrm{C}$.

Figure 3. EBSD measurement of the steel deformed at $710^{\circ} \mathrm{C}$ and $3 \times 10^{-4} \mathrm{~s}^{-1}$ showing the grain spread misorientation (from blue to red) and the grain (black) and subgrain (white) boundaries. Compression axis is vertical 
At low temperatures and low strain rates the EBSD measurements of the deformed ferrite showed a subgrain structure formed by DRV (Figure 3). In addition, at $710{ }^{\circ} \mathrm{C}$ and at the lowest strain rate, VN precipitates formed. Above $900{ }^{\circ} \mathrm{C}$ no ferrite was observed and dynamic recrystallization of austenite took place increasing the ductility.

Damage. In the Ti662 with a lamellae starting microstructure, formation of pores at the alpha/beta interface is observed. The alpha grains colonies have the highest strength while the $\beta$ phase is inherently soft at the deformation temperature [20]. Thus, heterogeneous deformation takes place, resulting in stress concentrations at the triple junction grain boundaries. If not relieved, these stresses produce cracks or pores nucleate at this interlayer.

In the case of the low alloy steel, porosity was observed at low strain rate tensile tests in the range of $700-800{ }^{\circ} \mathrm{C}$. This is the result of many factors: deformation below the critical recrystallization temperature of austenite, formation of precipitates at the austenite grain boundary promoted by long time of exposure and increased by their low solubility in ferrite, and the long-time of deformation needed for pore coarsening.

Flow behaviour. Some examples of the flow curves can be seen in the respective publications. In all the cases, softening due to adiabatic flow could be observed above $1 \mathrm{~s}^{-1}$ of strain rate. In general:

- The experiments for the Ti662 alloy were designed to simulate the possible changes in the temperature before deformation in industrial processes. In all the cases the phase equilibrium before deformation was not reached, and dynamic transformation took place during compression. The non-equilibrium state is verified in Figure 4. The sample held during 40 minutes at $650^{\circ} \mathrm{C}$ before deformation shows higher stress values compared to the one held during 30 seconds due to the formation of fine secondary alpha.

- Ti662 with lamellae structure presents more softening than a globular one [8]. This can be due to the damage of the material (pores at the triple grain boundary).

- Some peak stresses (discontinuous yielding) were also observed for Ti55531 in both alpha + beta and beta fields, probably related to the effect of alloying elements.

- The low alloy steel showed softening in the flow curves at low strain rates mainly attributed to ferrite phase transformation below the critical temperature, which is accelerated due to deformation.
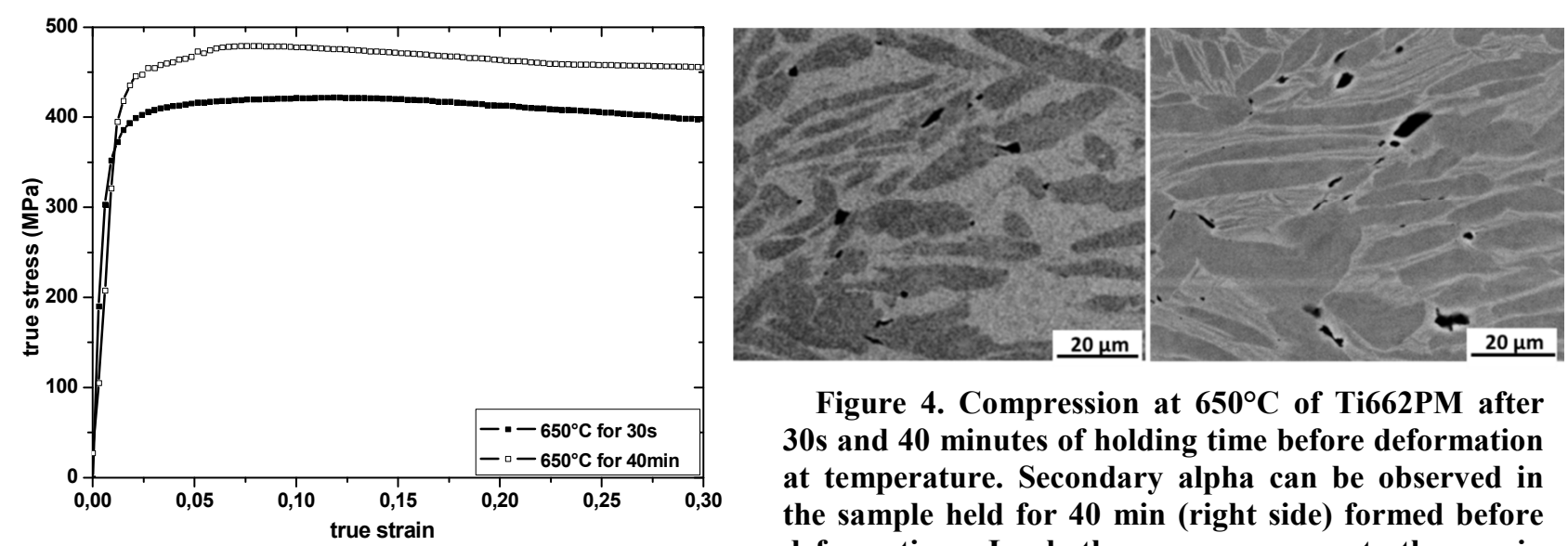

Figure 4. Compression at $650^{\circ} \mathrm{C}$ of Ti662PM after 30 s and 40 minutes of holding time before deformation at temperature. Secondary alpha can be observed in the sample held for $\mathbf{4 0}$ min (right side) formed before deformation. In both cases, pores at the grain boundaries are observed

Hot deformation models. In the following section, constitutive equations and efficiency of dissipation $\left(\eta_{\text {Murty and Rao }}\right)$ calculations are presented.

The flow data of Ti662 produced by powder metallurgy was correlated with the creep equation (Eq 2), and $\mathrm{n}=11$ for $650^{\circ} \mathrm{C}$ and $\mathrm{n}=5.8$ for $750^{\circ} \mathrm{C}-950^{\circ} \mathrm{C}$ was found. Due to large stresses, the flow was correlated with temperature and strain rate using Eq 4. A value of $n=5$ was found for all the temperatures and strain rates, and a $Q=398 \mathrm{~kJ} / \mathrm{mol}$. A good correlation of $\mathrm{Z}$ with the left side of equation 4 using these parameters is shown in Figure 5. The values of $\mathrm{h}$ are independent of the strain rate at temperatures below $850^{\circ} \mathrm{C}$, where up to $30 \%$ of alpha phase is present in the material. 
Due to the non equilibrium state, in the tests at $\mathrm{T} \leq 850^{\circ} \mathrm{C}$ alpha phase is precipitating during deformation, and $\mathrm{T}=950^{\circ} \mathrm{C}$, alpha phase transforming into beta during deformation, both effects increased at lower strain rates. The first process should refine the microsctructure, while the second should retard the restoration mechanism.

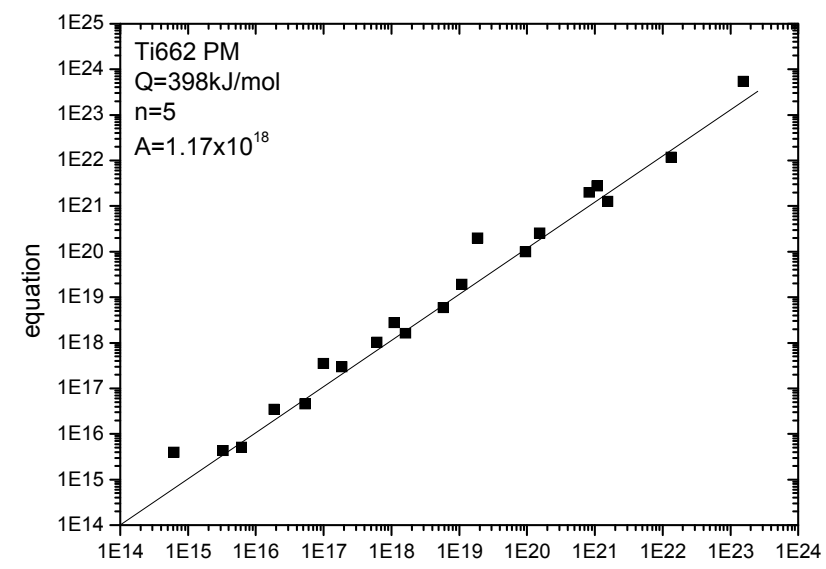

a)

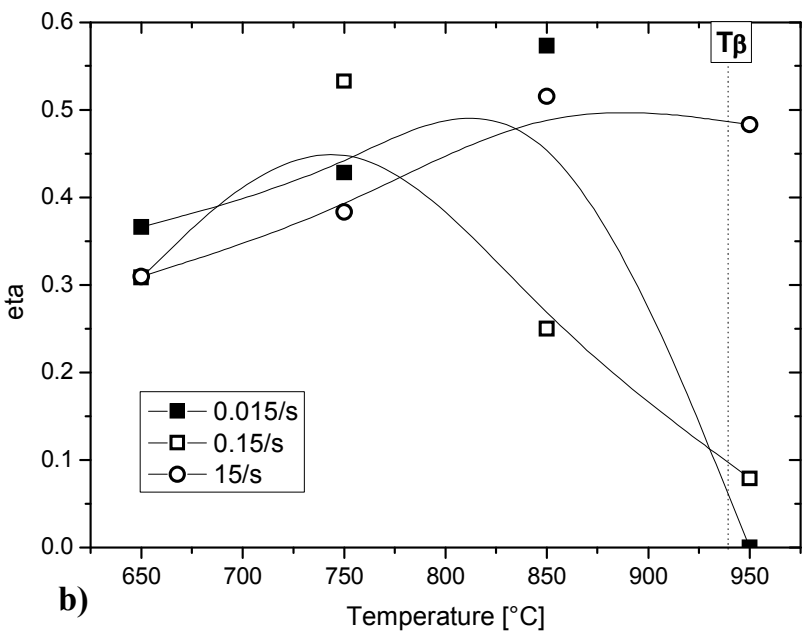

b)

Figure 5. Ti662 PM flow data correlated with a) sinh constitutive equation and b) modified DMM

Flow data was correlated with Eq 2 for the Ti55531 material, and a value of $n=4.5$ was found for all the temperatures and strain rates. By using Eq 4 with $\alpha=0.009 \mathrm{MPa}^{-1}$ it was found that $\mathrm{n}=3$ and that the apparent activation energies values were $220 \mathrm{~kJ} / \mathrm{mol}$ and $172 \mathrm{~kJ} / \mathrm{mol}$ for high and low strain rates, respectively Figure 6a. The $\mathrm{Q}$ for self-diffusion of beta phase is reported to be $135-153 \mathrm{~kJ} / \mathrm{mol}$ $[21,22]$. These values are related to recovery of the beta phase, which is the main mechanism in alpha-beta and beta field, and which is more difficult at high strain rates. Figure $6 \mathrm{~b}$ show the values of $\eta$ calculated using Eq 8 as a function of the temperatures for different strain rates. It can be seen for Ti5531 that large values of $\eta$ are predicted at low strain rates, related to restoration mechanisms taking place (recovery). The value decreases by increasing the strain rate.
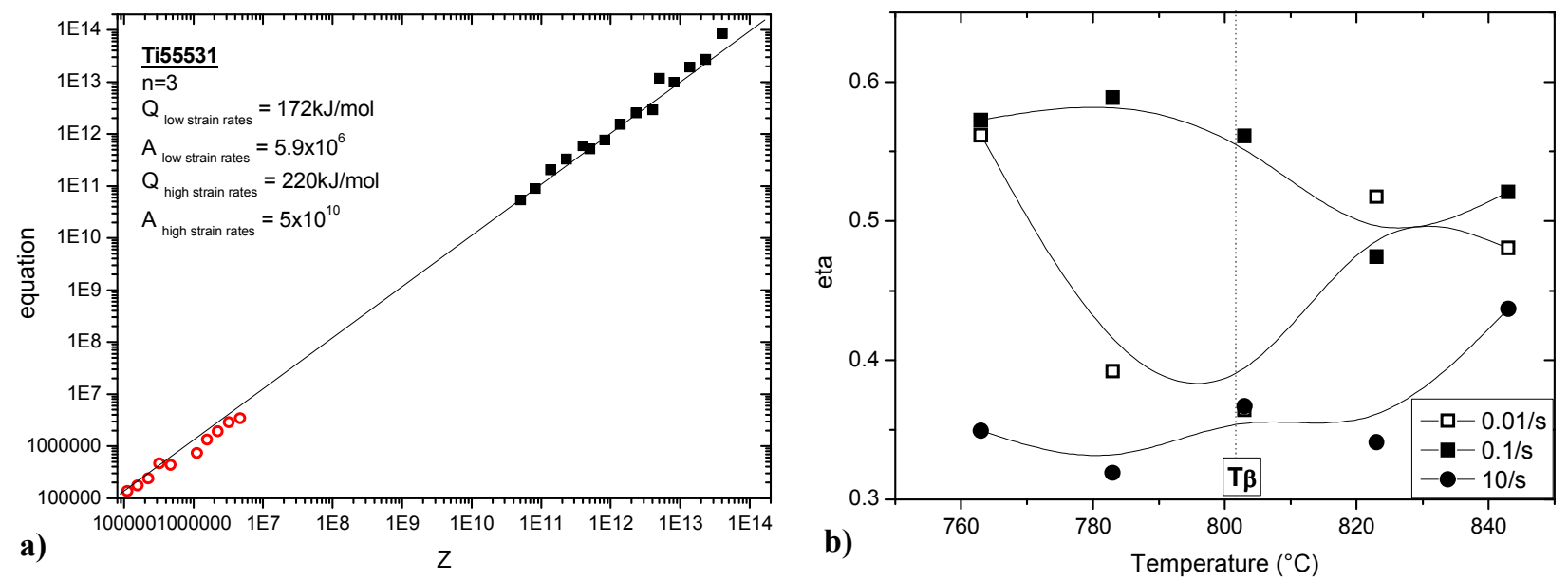

Figure 6. T55531flow data correlated with a) sinh constitutive equation and b) modified DMM

The calculation of Ti64 in a large range of temperatures and strain rates results in an increment of the $\eta$ value by both, increasing the temperature and decreasing the strain rate. By reaching the beta transus temperature, the $\eta$ value remains more or less constant, in agreement with the recovery mechanism which takes place in the beta phase. The $\eta$ value is also sensitive to the beta transus temperature. 
The use of Eq 2 to correlate the flow data with both, temperature and strain rate gave a value of $\mathrm{n}=12$, meaning power law creep down, while using $\mathrm{Eq} 4, \mathrm{n}=4$ related to dislocation climbing and sliding was obtained using $\alpha=0.02$. The energy of activation $Q$ was calculated to be $384 \mathrm{~kJ} / \mathrm{mol}$, although it does not correlate very well for small $Z$ values (low temperature and low strain rate) as observed in Figure 8, but it is well correlated at higher $\mathrm{Z}$ values for the $\mathrm{Q}$ of the self-diffusion in austenite $(\mathrm{Q}=280 \mathrm{~kJ} / \mathrm{mol})$ [23], the selfdiffusion of ferrite in the bulk $(\mathrm{Q}=55.7$ $\mathrm{kJ} / \mathrm{mol})$ and at the grain boundary $(\mathrm{Q}=289$ $\mathrm{kJ} / \mathrm{mol}$ ).

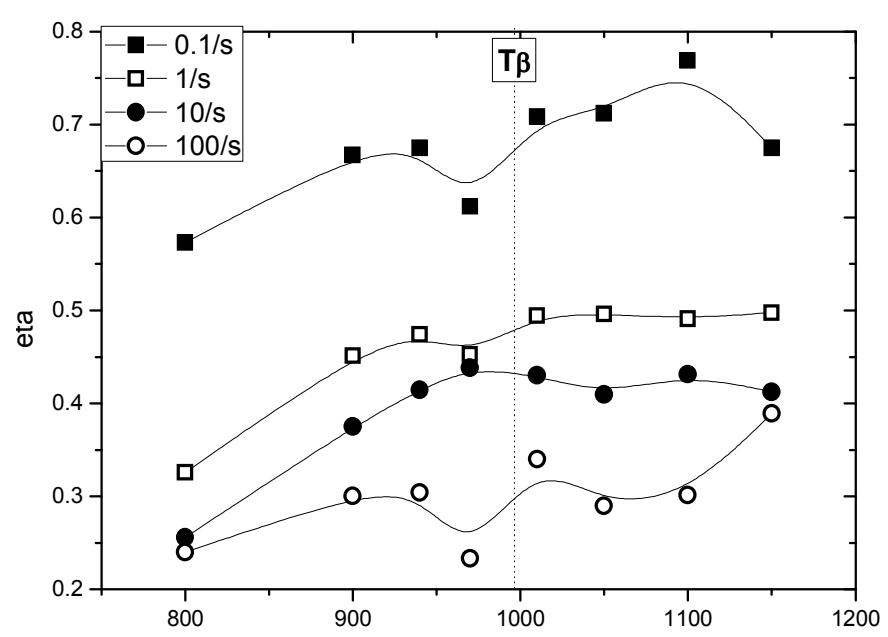

Figure 7. Ti64 flow data correlated with the modified DMM

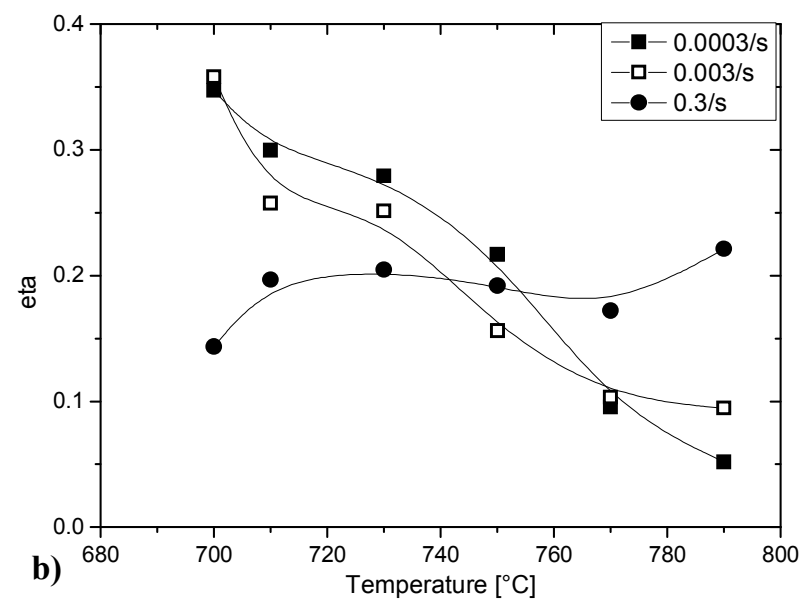

a)

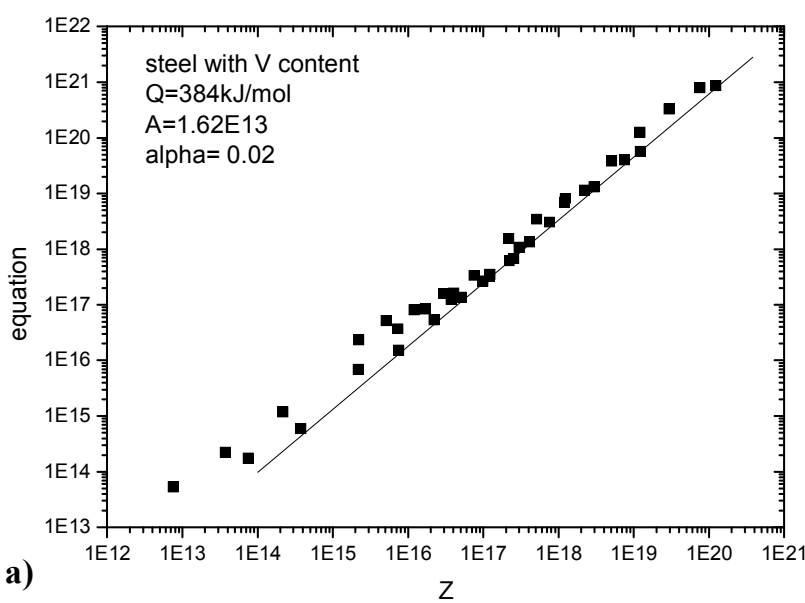

Figure 8 Low alloyed steel flow data correlated with a) sinh constitutive equation and b) modified DMM

The low strain rate area was dominated by the largest $\eta$ at low temperatures, which promote both, the ferrite formation and the dynamic restoration of this formed phase. Furthermore, porosity was observed at the ferrite/prior austenite interface and $\mathrm{VN}$ rich precipitates form. At high strain rates or at high temperatures, where the formation of strain induced ferrite is negligible, deformation bands in austenite place, which correlates well with low $\eta$ values.

\section{Summary and conclusions}

In this study of the hot deformation behaviour steel and titanium alloys was summarized using different materials models and experimental assessments. Accurate experimental set up and high quality of the data is essential for the description of the hot deformation.

The dynamic deformation mechanisms can be detected after deformation and microstructure freezing and metallographic observations. When recovery occurs, the EBSD technique, is required. For allotropic materials such as titanium alloys and steels, the high temperature phase can be frozen sometimes and the study of the microstructure proceeded as before. If water quenching results in a phase transformation, both LOM and SEM-EBSD can still be used qualitatively as well as quantitatively in the reconstruction of the high temperature phase. Meta-dynamic recrystallization and static recrystallization can take place after deformation if the temperature is not abruptly decreased. If this effect is not taken into account a misinterpretation of the deformed microstructure is made. 
The efficiency of power dissipation is deeply correlated with the $\mathrm{n}$ exponent. Furthermore, the calculation of the power dissipation by integrating $J$ (or $\mathrm{G}$ ) can be used for any flow behaviour and is more sensitive than $n$ values. The correlation with the microstructure showed that large values of any of these parameters are related to diffusion controlled processes such as dynamic recovery, dynamic recrystallization, phase transformations and pore coarsening. Low values should be related to diffusionless processes such as deformation bands formation, twinning and brittle crack. The efficiency of power dissipation of different materials can be interpreted and are intended to be used as prediction maps from the flow data as a function of the strain.

\section{Acknowledgments}

The authors would like to thank FWF (Austrian Science Fund) for funding project number [P22238-N22], Voestalpine Stahl GmbH and Böhler Schmiedetechnik for the provision of the material and to USTEM (Vienna University of Technology) for the provision of the FIB-SEM EBSD facilities.

\section{References}

[1] R.M. Miller, T.R. Bieler and S.L. Semiatin. Scripta Mater. 40-12 (1999) 1387-1393

[2] A. Arieli und A. Rosen. Metall. Mater. Trans. A. 8-10, (1977) 1591-1596

[3] C.M. Sellars, W.J. McG. Tegart. Acta Metall. 14 (1966) 1136

[4] N.E. Dowling. Mechanical Behaviour of Materials: Engineering Methods for Deformation, Fracture and Fatigue. 3rd edition 2007. Pearsons Prentice Hall

[5] Y.V.R.K Prasad, H.L. Gegel, S.M. Doraivelu, J.C. Malas, J.T. Morgan, K.A. Lark, D.R. Barker. Metall. Trans. A15, 10 (1984) 1883

[6] S.V.S Narayana Murty, B. Nageswara Rao. J. Mater. Sci. Lett. 17. (1998) 1203

[7] S.V.S. Narayana Murty, B. Nageswara Rao. J. Mater. Process. Technol. 104 (2000) 103

[8] C. Poletti, H.P. Degischer, S. Kremmer, W. Marketz. Mater. Sci. Eng. A486 1-2 (2008) 127-137

[9] F. Warchomicka, C. Poletti, M. Stockinger, T. Henke. Int. J. Mater. Form. 3-1 (2010) 215-218

[10] F. Warchomicka, C. Poletti, M. Stockinger. Mater. Sci. Eng. A528, 28 (2011) 8277 - 8285.

[11] C. Poletti, S. Großeiber, S. Ilie, H. P. Degischer. THERMEC' 2011, International Conference on Processing \& Manufacturing of Advanced Materials, Quebec, 2011. In press.

[12] F. Warchomicka, M. Stockinger, H.P. Degischer. J. Mater. Process. Technol. 177, 1-3 (2006) 473-477

[13] M. Cabibbo, W. Blum, E. Evangelista, M. Kassner, M. Meyers. Metall. Mater. Trans. A39, 1 (2008) 181

[14] N.G. Jones, R.J. Dashwood, D. Dye, M. Jackson, Mater. Sci. Eng. A490 (2008) 369

[15] F. Warchomicka, C. Poletti, M. Stockinger. In proceedings of Ti2011. In Press

[16] F.J. Humphreys, M. Hantherly. Recrystallization and related annealing phenomena, second ed., Pergamon, New York, 2004.

[17] H.J.McQueen, O. Knustad, N. Ryum, J.K. Solberg, Scr. Metall. 19 (1985) 73

[18] P. Cizek, B.P. Wynne. Mater. Sci. Eng. A230 (1997) 88

[19] Vladimir V. Basabe, John J. Jonas and Hesameddin Mahjoubi. ISIJ International 514 (2011) 612-618

[20] T. Seshacharyulu, S.C. Medeiros, W.G. Frazier and Y.V.R.K. Prasad. Mater. Sci. Eng. A284 (2000), 184-194.

[21] N.E. Walsoe de Reca, C.M. Libanati, Acta Metall. 16 (1968) 1297

[22] J. F. Murdock, T.S. Lundy, E.E. Stansbury, Acta Metall.12 (1964) 1033

[23] H.J. Frost and M.F. Ashby, Deformation-mechanism maps: the plasticity and creep of metals and ceramics, Pergamon Press, Oxford (1982). 